\title{
Critical roles of Bim in T cell activation and $T$ cell-mediated autoimmune inflammation in mice
}

\author{
Maciej W. Ludwinski, Jing Sun, Brendan Hilliard, Shunyou Gong, Fan Xue, Ruaidhri J. Carmody, \\ Jennifer DeVirgiliis, and Youhai $H$. Chen
}

Department of Pathology and Laboratory Medicine, University of Pennsylvania School of Medicine, Philadelphia, Pennsylvania, USA.

\begin{abstract}
Bim, the B cell lymphoma 2-interacting (Bcl2-interacting) mediator, maintains immunological tolerance by deleting autoreactive lymphocytes through apoptosis. We report here that Bim is also, paradoxically, required for the activation of autoreactive $\mathrm{T}$ cells. Deletion of Bim in hematopoietic cells rendered mice resistant to autoimmune encephalomyelitis and diabetes, and Bim-deficient $\mathrm{T}$ cells had diminished cytokine production. Upon $T$ cell receptor activation, Bim-deficient $T$ cells exhibited severe defects in both calcium release and dephosphorylation of nuclear factor of activated T cells (NFAT) but maintained normal levels of activation of NF- $\kappa B$ and MAPKs. The defective calcium signaling in Bim-deficient $T$ cells was associated with a significant increase in the formation of an inhibitory complex containing $\mathrm{Bcl} 2$ and the inositol triphosphate receptor $\left(\mathrm{IP} \mathrm{P}_{3} \mathrm{R}\right)$. Thus, in addition to mediating the death of autoreactive $\mathrm{T}$ cells, $\mathrm{Bim}$ also controlled $\mathrm{T}$ cell activation through the $\mathrm{IP}_{3} \mathrm{R} /$ calcium/NFAT pathway. These results indicate that a single protein is used to control both the activation and apoptosis of autoreactive $T$ cells and may explain why Bim-deficient mice do not reject their own organs despite lacking thymic negative selection.
\end{abstract}

\section{Introduction}

Apoptosis, or programmed cell death, is essential for the maintenance of cellular homeostasis in multicellular organisms. It is characterized by a controlled destruction of cellular structures through proteolysis of vital cellular components. Apoptosis can be mediated by at least 2 distinct pathways: the mitochondrial pathway (also called the stress or intrinsic pathway) and the death receptor pathway (also called the extrinsic or mitochondria-independent pathway). Unlike the death receptor pathway, which is activated by death ligands, the mitochondrial pathway is activated by agents that perturb, either directly or indirectly, the integrity of the mitochondrial outer membrane. These include cytotoxic cytokines, antigens, and reactive oxygen species (1-3). The "stressed" mitochondria release cytochrome $c$ to the cytosol, which in turn activates the caspase cascade through Apaf- 1 and caspase-9 (4). Unlike the death receptor pathway, the mitochondrial pathway is directly controlled by the B cell lymphoma 2 (Bcl2) family of proteins.

The Bcl2 family consists of 3 classes of proteins that can either promote or inhibit the mitochondrial pathway of apoptosis $(5,6)$. The first class is called Bcl2-like antiapoptotic factors. These factors all contain 3 to $4 \mathrm{Bcl} 2$ homology (BH) domains, which are required for their antiapoptotic function. This group includes $\mathrm{Bcl} 2, \mathrm{Bcl}-\mathrm{xL}$, Bcl-w, A1/Bfl-1, Boo/Diva/Bcl-B, and Mcl-1 (5, 6). Bcl2 is the bestcharacterized member of this group. It blocks apoptosis by pre-

Authorship note: Maciej W. Ludwinski and Jing Sun contributed equally to this work.

Conflict of interest: The authors have declared that no conflict of interest exists.

Nonstandard abbreviations used: $\mathrm{Bcl} 2$, B cell lymphoma 2; $\mathrm{BH}, \mathrm{Bcl} 2$ homology; CY, cyclophosphamide; $\mathrm{IP}_{3} \mathrm{R}$, inositol triphosphate receptor; $\mathrm{LDA}$, limiting dilution analysis; MBP, myelin basic protein; MOG, myelin oligodendrocyte glycoprotein; NFAT, nuclear factor of activated T cells; PMA, phorbol myristate acetate; STZ, streptozotocin; T1D, type 1 diabetes.

Citation for this article: J. Clin. Invest. 119:1706-1713 (2009). doi:10.1172/JCI37619. serving the integrity of the outer mitochondrial membrane, thus preventing cytochrome $c$ release. It neutralizes the activities of proapoptotic members of the family by directly interacting with them. Bcl2-deficient mice show defects in renal development and undergo premature loss of lymphoid cells and melanocytes, resulting in immunodeficiency and loss of hair pigmentation, respectively (7). The second class is called Bax-like proapoptotic factors. These factors contain BH1-BH3 domains, which act exclusively in a proapoptotic fashion. This group consists of Bax, Bak, and Bok/Mtd $(5,6)$. The third class is called BH3-only proapoptotic factors. These members share only a 9-amino acid BH3 domain with other Bcl2 family members. They include Bim (Bcl2-interacting mediator), Bid, Bad, Bik/Nbk, Blk, Hrk/DP5, Noxa, Puma/Bbc3, Bnip3, Bmf, and Bcl-Gs $(1,5,6)$.

Bim was initially identified as a Bcl2-interacting protein (8). It exists in several isoforms, of which Bims, Bim $_{L}, B_{\mathrm{EL}}, \mathrm{Bim}_{\mathrm{AD}}$, and $\operatorname{Bim}_{\mathrm{G}}$ seem to be the most potent inducers of apoptosis $(8,9)$. Bim is constitutively expressed in many cell types but is maintained in an inactive form through binding to the microtubule-associated dynein motor complex (10). Cytokines, antigens, and cytotoxic agents can activate the Bim pathway through at least 3 different mechanisms: (a) by releasing it from the dynein motor complex or the antiapoptotic members of the Bcl2 family; (b) by increasing its mRNA level through transcriptional regulation; and (c) by increasing its protein level through proteasome-dependent regulation of protein degradation (1-3). For example, TCR ligation can significantly increase Bim protein levels in T cells (11). Cytokines that activate JNK or the forkhead family of transcriptional factors can also regulate Bim expression and function (12-14). The mechanisms through which Bim induces apoptosis are not well understood. Recent studies indicate that Bim acts upstream of Bax and may directly activate Bax and Bak-like proteins in certain cell types $(3,15,16)$. This has led to the recognition that Bim serves as 

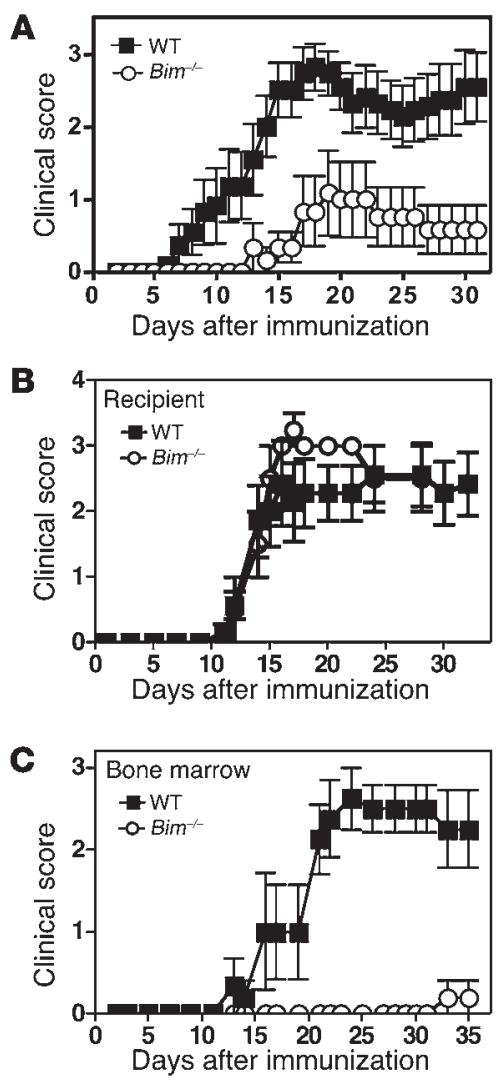

a key initiator of the mitochondrial pathway of apoptosis. However, direct interaction of Bax with Bim was observed in some cells (e.g., neurons) $(12,16)$ but not others $(8)$. Additionally, Bim may also initiate apoptosis by neutralizing or modifying $\mathrm{Bcl} 2$ or $\mathrm{Bcl} 2$ like prosurvival proteins $(1,2,17)$. Bim is critical for apoptosis and homeostasis in the lymphoid and myeloid compartments. Bimknockout mice have abnormally high numbers of lymphoid and myeloid cells (17). T cells, B cells, granulocytes, and monocytes are increased 2- to 4-fold in peripheral tissues compared with those in WT animals. With age, Bim-knockout mice develop splenomegaly, lymphadenopathy, and hypergammaglobulinemia (17). Using experimental models of negative selection, Bouillet et al. discovered that Bim-deficient mice have a severe defect in negative selection of autoreactive T cells in the thymus (11). Death of thymocytes recognizing superantigens (Mtv9 and Staphylococcus enterotoxin B) and male antigen $\mathrm{HY}$ was almost completely blocked in $\mathrm{Bim}^{-/-}$mice (11). Deletion of antigen-activated T cells during the shutdown of immune responses is also hindered in these mice (18).

While it is well recognized that members of the $\mathrm{Bcl} 2$ family are crucial regulators of the mitochondrial pathway of apoptosis, the roles of most of these proteins in organ-specific autoimmune diseases are not known. We report here that Bim plays an unexpected role in $\mathrm{T}$ cell activation and $\mathrm{T}$ cell-mediated autoimmunity.

\section{Results}

Bim deficiency in hematopoietic cells renders mice resistant to autoimmune encephalomyelitis and diabetes. To determine the roles of Bim in autoimmunity, we first studied EAE in $\mathrm{Bim}^{-/-}$mice. Young $\mathrm{Bim}^{-/-}$mice $(<14$ weeks old) are healthy and do not have developmental problems, whereas old $\mathrm{Bim}^{-/-}$mice (>14 weeks old) develop lymphadenopa-

\section{Figure 1}

Effects of Bim deficiency on the development of autoimmune encephalomyelitis. Five -to six-week-old WT and Bim${ }^{-1-}$ C57BL/6 mice $(n=6)$ (A), irradiated CD45.1+ WT and CD45.2+ Bim $^{-/-}$C57BL/6 mice $(n=6)$ that received CD45.1+ WT bone marrow $(B)$, and irradiated CD45.1+ WT C57BL/6 mice $(n=6)$ that received CD45.1+ WT or CD45.2+ $\mathrm{Bim}^{-/-}$bone marrow (C) were immunized with MOG to induce EAE as described in Methods. Data are presented as mean $\pm S D$ of EAE scores and are representative of 2-3 independent experiments. The differences between WT and $\mathrm{Bim}^{-/}$groups are statistically significant $(P<0.001)$ for panels $\mathbf{A}$ and $\mathbf{C}$ but not $\mathbf{B}$.

thy and inflammatory kidney diseases (17). For these reasons, only 5- to 7-week-old young mice were used in this study. Thus, Bim-1C57BL/6 mice and their WT littermate controls were immunized with myelin oligodendrocyte glycoprotein 38-50 (MOG 38-50) peptide and monitored for EAE by both physical examination and histochemistry (19). EAE developed in all (100\%) control mice, starting approximately 6 days after immunization (Figure 1A). The disease took a chronic progressive course, with a $30 \%$ mortality rate. In contrast, in the $\mathrm{Bim}^{-/-}$group, only $50 \%$ of mice developed symptoms of EAE, and no mice died of the disease. The onset of the disease was delayed by approximately 4 days $(14 \pm 1.1$ and $10 \pm 0.9$ days in WT and $\mathrm{Bim}^{-/}$mice, respectively; $\left.P<0.05\right)$, whereas recovery significantly accelerated in $\mathrm{Bim}^{-1-}$ mice (18\% and $100 \%$ in WT and $\mathrm{Bim}^{-/-}$mice, respectively; $P<0.05)$. Consistent with these clinical findings, the degree of encephalomyelitis was also significantly reduced in the $\mathrm{Bim}^{-/-}$group (Figure 2, A and B).

Since Bim is expressed not only by cells of the immune system but also by cells of the central nervous system, we next investigated whether Bim expressed by different organ systems played different roles in EAE. Thus, bone marrow chimeric mice were generated by either injecting WT bone marrow cells into irradiated $\mathrm{Bim}^{-/-}$or WT recipients (Figure $1 \mathrm{~B}$ ) or by injecting $\mathrm{Bim}^{-/}$or WT bone marrow cells into irradiated WT recipients (Figure 1C). Mice were then immunized with MOG peptide to induce EAE as in Figure 1A. Remarkably, Bim deficiency in bone marrow-derived cells alone was sufficient to prevent EAE (Figure 1C), whereas Bim deficiency in non-bone marrow-derived cells had no effect (Figure 1B). The frequency and/or the number of donor-derived cells in the recipient mice was determined by flow cytometry before immunization and after the end of the experiment. Although the percentages of lymphoid and myeloid cells were comparable in mice that received WT and Bim-deficient cells, the number of donor-derived cells was increased by approximately 2 -fold in the spleens of mice that received Bim-deficient cells as compared with those that received WT cells. Taken together, these results indicate that Bim expressed by hematopoietic cells plays an indispensable role in the development of autoimmune inflammation in the CNS.

To determine whether the roles of Bim observed in EAE could be extended to other autoimmune disease models, we studied type 1 diabetes (T1D) in both C57BL/ 6 and NOD.C57BL/ 6 congenic mice. Consistent with previous reports $(20,21)$, multiple low-dose injections of streptozotocin (STZ) induced diabetes in approximately $54 \%$ of WT C57BL/6 mice, which was characterized by severe hyperglycemia (Supplemental Figure 1, A and B; supplemental material available online with this article; doi:10.1172/ JCI37619DS1) and insulitis (Supplemental Figure 2). In contrast, only $15 \%$ of $\mathrm{Bim}^{-/-}$C57BL/ 6 mice developed STZ-induced diabetes, with significantly reduced insulitis (Supplemental Figure 1, A 
A
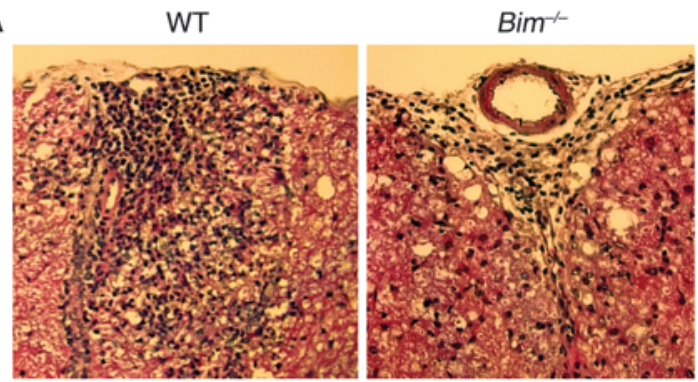

B

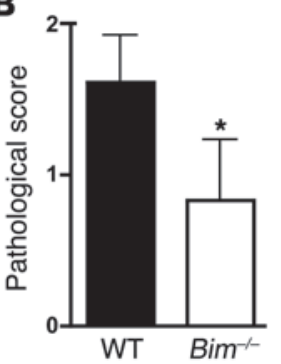

C
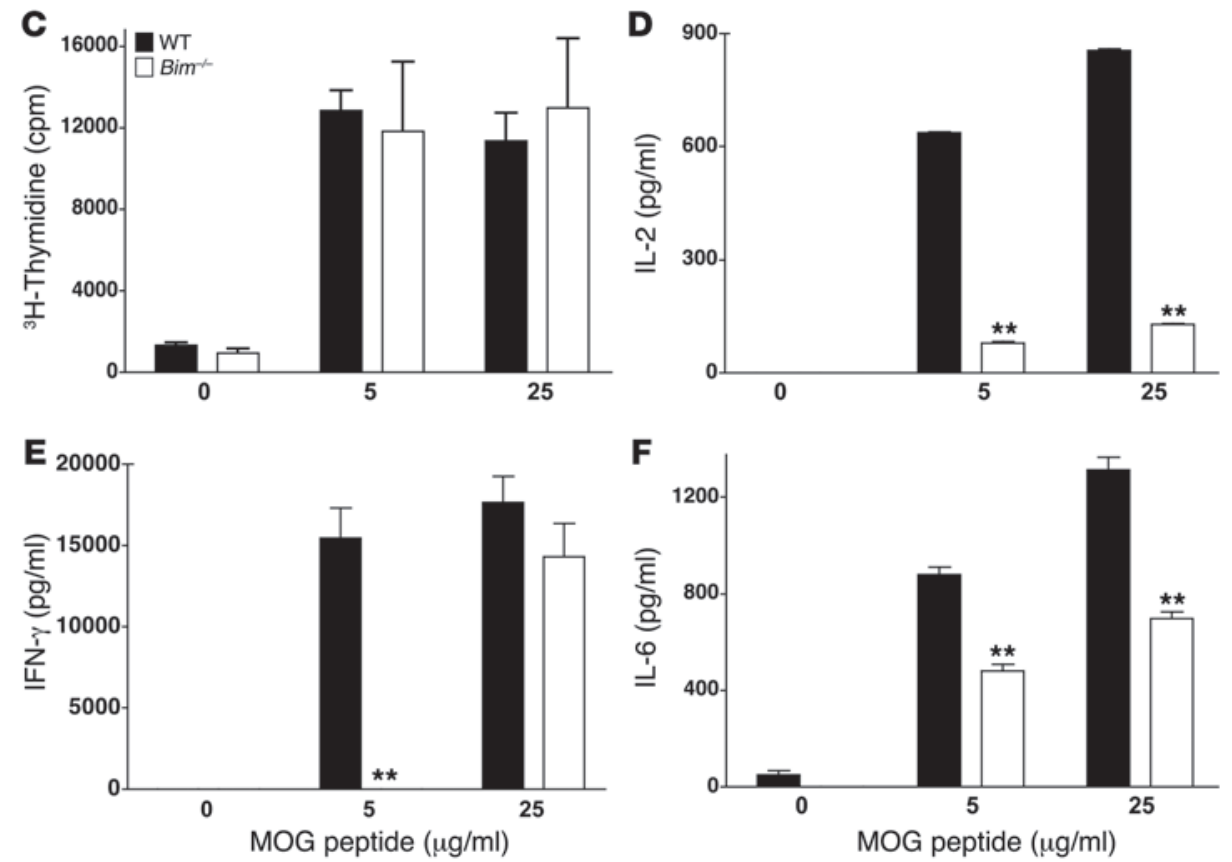

F

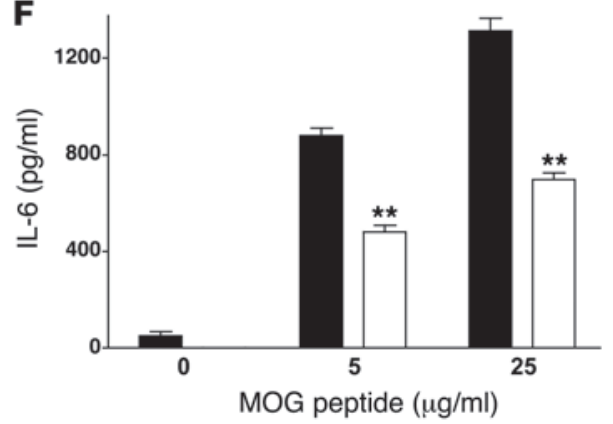

\section{Figure 2}

Reduced neural inflammation and antimyelin $T$ cell immunity in Bim-deficient mice. (A and B) Mice $(n=6)$ were treated as in Figure $1 \mathrm{~A}$ and sacrificed 31 days after immunization. Spinal cord sections were stained with H\&E. (A). Original magnification, $\times 200$. Data in panel $B$ represent mean $+S D$ of pathological scores of all mice $(n=6)$, with 10 sections per mouse examined. (C-F) Mice were treated as in Figure $1 \mathrm{~A}$ and sacrificed 10 days after immunization. Splenocytes, $5 \times 106 /$ well, were cultured with or without different concentrations of MOG38-50 peptide. Culture supernatants were collected 40 hours later and tested for cytokines by ELISA. For proliferation assay, cells were pulsed with ${ }^{3} \mathrm{H}$-thymidine and radioactivity determined 16 hours later. Data presented are representative of 3 experiments. ${ }^{*} P<0.05 ;{ }^{* *} P<0.01$. and B, and Supplemental Figure 2). More strikingly, $\mathrm{Bim}^{-/-}$NOD. $\mathrm{C} 57 \mathrm{BL} / 6$ congenic mice were completely resistant to the development of diabetes even after 2 administrations of cyclophosphamide (CY), which is known to significantly accelerate T1D; in contrast, approximately $80 \%$ of NOD.C57BL/6 WT littermates developed T1D under the same conditions. Spontaneous diabetes could not be studied in $\mathrm{Bim}^{-/-}$mice because of their significantly reduced life span (17). CY may accelerate the development of T1D by inducing apoptosis of Treg cells (22). However, we found that CY-induced apoptosis of Tregs as well as that of $\mathrm{CD}^{+}, \mathrm{CD}^{+}$, and $\mathrm{CD} 19^{+}$cells was not affected by Bim deficiency (our unpublished data).

To determine whether Bim deficiency in $\mathrm{T}$ lymphocytes was responsible for the reduced diabetes in Bim-deficient mice, we transferred WT and Bim ${ }^{-/}$splenic T cells into Rag1-knockout mice (which do not have lymphoid cells). One week after T cell transfer, mice were injected with low-dose STZ for 5 days to induce diabetes. By the fourth week, $60 \%$ of mice that received WT T cells developed diabetes with severe hyperglycemia; in contrast, only $18 \%$ of mice that received Bim-deficient T cells developed T1D (Supplemental Figure 3). Rag1-knockout mice that received no T cells did not develop T1D (our unpublished data). Taken together, these results establish that Bim expressed by $\mathrm{T}$ cells plays a crucial role in the development of autoimmune diseases.

It is to be noted that although the total numbers of CD $4^{+} \mathrm{CD} 25^{+}$ Treg cells and $\mathrm{CD} 4^{+} \mathrm{CD} 25^{-}$non-Treg cells were significantly increased in the spleens of aged Bim-deficient mice as compared with WT mice, the percentages of these cell types were not affected by the Bim deficiency. Additionally, Bim does not appear to mediate cyclophosphamide-induced death of lymphocytes in vivo. Specifically, 4 days after a single injection of cyclophosphamide $(200 \mathrm{mg} / \mathrm{kg})$, the total number of splenic Treg cells was reduced by $42 \%$ and $38 \%$ in WT and Bim-deficient NOD mice, respectively, whereas those of $\mathrm{CD}^{+} \mathrm{CD}^{-} 5^{-}$non-Treg cells were reduced by $45 \%$ and $44 \%$ in WT and Bim-deficient NOD mice, respectively. CD19+ B cells were more sensitive to cyclophosphamide-induced death; these percentages were reduced by $83 \%$ and $86 \%$ in WT and Bimdeficient NOD mice, respectively.

Bim-deficient mice develop reduced T cell responses to self-neural and pancreatic antigens. Autoreactive $\mathrm{T}$ cells are both initiators and effectors of EAE and T1D. To determine whether activation and differentiation of autoreactive $\mathrm{T}$ cells are normal in Bim-deficient animals, splenocytes were collected from $\mathrm{Bim}^{-/-}$and WT mice and stimulated in vitro with purified self antigens. When stimulated with MOG peptide, $\mathrm{Bim}^{-1-}$ splenocytes from MOG-immunized C57BL/6 mice proliferated similarly to WT cells (Figure 2C). However, they produced significantly less IL-2, IL-6, and IFN- $\gamma$ than WT cells (Figure 2, D-F). Similarly, when stimulated with insulin or glutamic acid decarboxylase 65 (GAD65), antigens involved in the pathogenesis of T1D, Bim ${ }^{-/-}$splenocytes from NOD.C57BL $/ 6$ mice produced significantly less IL-2 and IFN- $\gamma$ than WT cells (Supplemental 

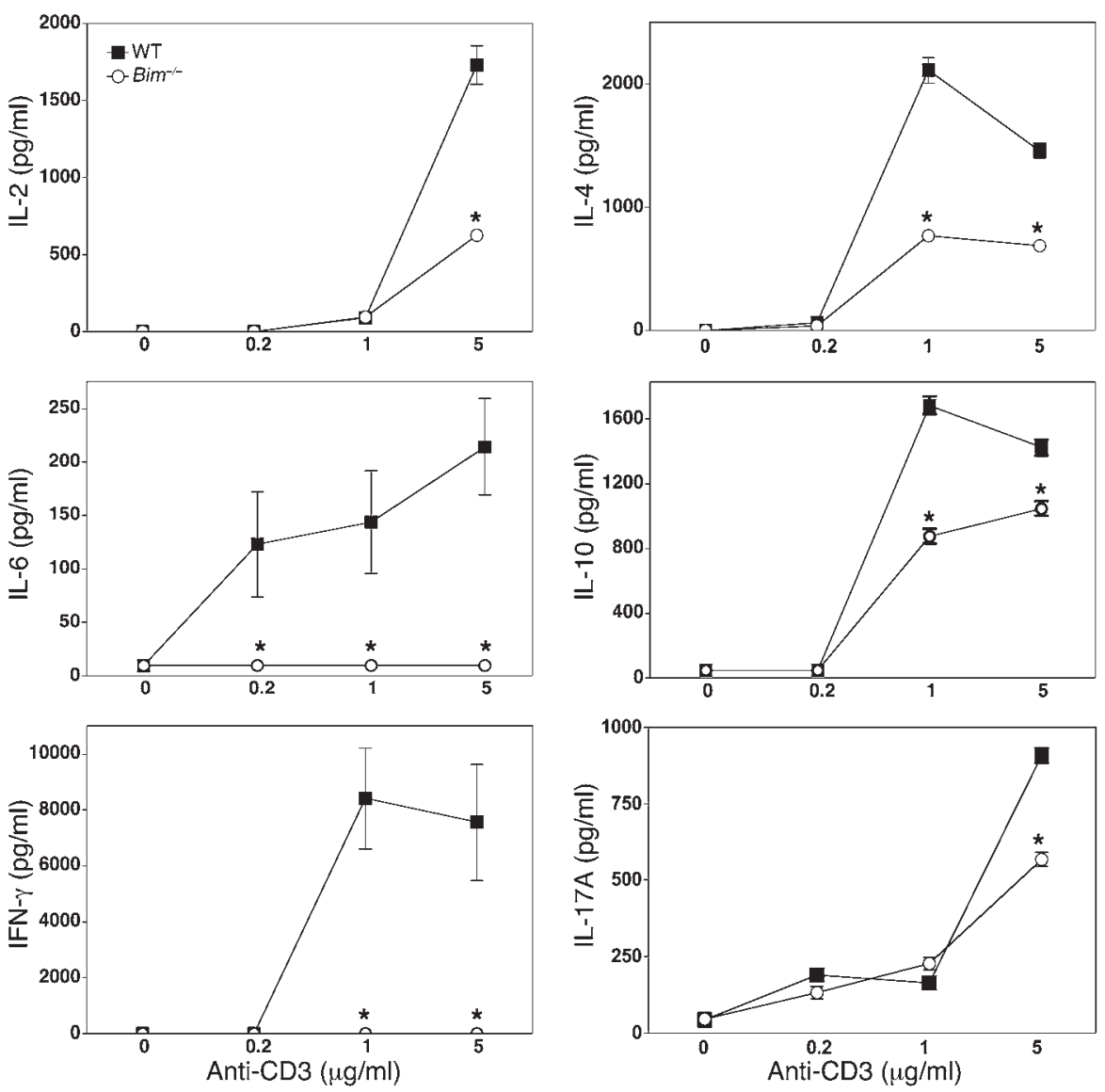

\section{Figure 3}

Defective cytokine production by Bim-deficient CD4+ $\mathrm{T}$ cells. CD4+ $\mathrm{T}$ cells isolated from naive WT and $\mathrm{Bim}^{-/-}$C57BL/6 mice $(n=4), 5-6$ weeks of age, were cultured in 96-well plates with different amounts of plate-bound anti-CD3 $(0-5 \mu \mathrm{g} / \mathrm{ml})$ and $2 \mu \mathrm{g} / \mathrm{ml}$ soluble anti-CD28. Culture supernatants were collected 18 hours later, and cytokine concentrations were determined by ELISA. Data show mean + SD of triplicate cultures and are representative of 3 independent experiments. ${ }^{*} P<0.01$.
Figure 4). Of note is that the effect of Bim deficiency on IFN- $\gamma$ production appears to be antigen and dose dependent, with the $25 \mu \mathrm{g} / \mathrm{ml}$ MOG-induced response the least affected. These results indicate that Bim may be required for the activation and function of autoreactive T cells.

Bim-deficient $T$ cells are defective in their cytokine gene expression following TCR activation. To determine whether $\mathrm{Bim}^{-1-} \mathrm{T}$ cells have an intrinsic defect in TCR-mediated activation, we purified CD4 ${ }^{+}$ $T$ cells and stimulated them with different concentrations of anti$\mathrm{CD} 3$ and anti-CD28. We found that $\mathrm{Bim}^{-/-} \mathrm{T}$ cells had a global defect in cytokine production affecting all cytokines tested, which included IL-2, IL-4, IL-6, IL-10, IL-17A, and IFN- $\gamma$ (Figure 3). Consistent with these results, overexpression of Bim in EL-4 T cells significantly increased IL-2 production (Supplemental Figure 5). The defect in $\mathrm{Bim}^{-/-} \mathrm{T}$ cells appears to lie upstream of the cytokine synthesis because mRNA expression of selected cytokines (IL-2, IL-6, and IL-17A) was also significantly reduced in these cells (Figure 4, A-C). However, despite an increase in p27 levels (Supplemental Figure 6), $\mathrm{Bim}^{-1-} \mathrm{T}$ cells did not show a significant defect in proliferation (our unpublished data). Additionally, following stimulation with phorbol myristate acetate (PMA) and ionomycin, $\mathrm{Bim}^{-/-} \mathrm{T}$ cells expressed levels of cytokines similar to those of WT T cells (Figure 4D and our unpublished data). Because PMA and ionomycin stimulate $T$ cells by activating protein kinase $\mathrm{C}$ and promoting calcium release from the $\mathrm{ER}$, these results indicate that the defect in Bim ${ }^{-1-}$ T cells may lie proximal to the TCR.

Bim-deficient $T$ cells have a selective defect in the calcium/nuclear factor of activated $T$ cells signaling pathway. To determine which signaling pathway is regulated by Bim, we studied TCR-induced activation of MAPK, NF- $\mathrm{BB}$, and nuclear factor of activated T cells (NFAT) pathways in WT and $\mathrm{Bim}^{-/-} \mathrm{T}$ cells. We found that activation-associated phosphorylation of JNK, ERK, and IKB was not affected by the Bim gene mutation (Figure 5A), indicating that the MAPK and NF- $\mathrm{\kappa B}$ signaling pathways are normal in $\mathrm{Bim}^{-/-} \mathrm{T}$ cells. In contrast, NFATc2 dephosphorylation, a critical step required for NFAT nuclear translocation and subsequent NFAT target gene activation, was significantly blocked in $\mathrm{Bim}^{-1-} \mathrm{T}$ cells (Figure 5, A and B). Thus, without TCR activation, NFATc2 existed primarily as a hyperphosphorylated protein in WT and Bim-deficient T cells (Figure 5, A and B). Upon anti-CD3 stimulation of WT T cells, essentially all NFATc2 proteins were dephosphorylated, leading to a significant reduction in their molecular weight. In contrast, only a marginal increase in dephosphorylated NFATc2 was noted in anti-CD3-treated $\mathrm{Bim}^{-/-} \mathrm{T}$ cells, with a significant portion of NFATc2 remaining phosphorylated.

NFAT dephosphorylation is mediated by calcineurin, a serine phosphatase that is activated by calcium/calmodulin following TCR ligation. To determine whether the calcium signaling is affected by Bim deficiency, we tested calcium release in T cells following TCR stimulation. We found that although calcium release occurred in $\mathrm{Bim}^{-1-} \mathrm{T}$ cells, its peak value was significantly reduced as compared with that in WT T cells (Figure 5C). The reduction in calcium flux was observed in Bim-deficient $\mathrm{T}$ cells treated with various concentrations of anti-CD3, i.e, 1,3 , and $9 \mu \mathrm{g} / \mathrm{ml}$. Taken together, these results establish that $\mathrm{Bim}^{-1-} \mathrm{T}$ cells have a significant defect in their calcium/NFAT signaling pathway. 

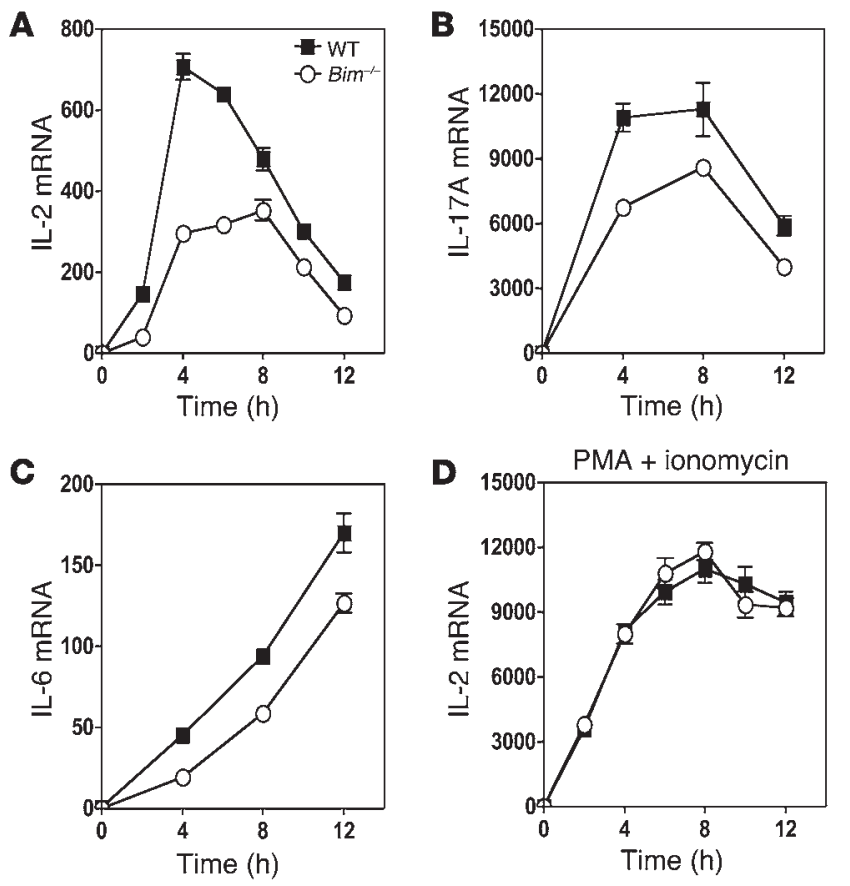

$\mathrm{Bcl} 2$ can modulate $\mathrm{ER} \mathrm{Ca}^{+2}$ release by forming a protein complex with inositol triphosphate receptor $\left(\mathrm{IP}_{3} \mathrm{R}\right)$ on the $\mathrm{ER}(23,24)$. To determine whether Bim interferes with this process, we measured the interaction between $\mathrm{Bcl} 2$ and $\mathrm{IP}_{3} \mathrm{R}$ by immunoprecipitation (Supplemental Figure 7). We found that $\mathrm{Bcl} 2$ associated with $\mathrm{IP}_{3} \mathrm{R}$ in murine $T$ cells, an association that was slightly increased upon $\mathrm{T}$ cell activation. Bim deficiency significantly increased Bcl2:

$\mathrm{IP}_{3} \mathrm{R}$ interaction, especially under activating conditions (Supplemental Figure 7). These data indicate that Bim may regulate $T$ cell activation through $\mathrm{IP}_{3} \mathrm{R}$.

The frequency of self-antigen-reactive T cells in Bim-deficient mice. Although it has been clearly demonstrated that negative selection of thymocytes recognizing super-antigens and male antigen $\mathrm{HY}$ was blocked in $\mathrm{Bim}^{-/-}$mice (11), to what degree Bim mediates the deletion of autoreactive cells involved in EAE and T1D has never, to our knowledge, been examined. To address

\section{Figure 5}

Defective NFAT activation and calcium influx of Bim-deficient $\mathrm{CD} 4^{+} \mathrm{T}$ cells. (A) CD4 ${ }^{+} \mathrm{T}$ cells were treated with anti-CD3 and anti-CD28 as in Figure 4A for the indicated times. Whole-cell lysates were blotted with antibodies to total or phosphorylated (p) IKB $\alpha, J N K 1 / 2$, ERK1/2, and NFATc2 as well as $\beta$-actin and p65. d-NFAT, dephosphorylated NFATC2. (B) Relative band intensities of phosphorylated NFATc2 (upper panel) and dephosphorylated NFATc2 (lower panel) shown in panel A as determined by densitometry. ( $C$ and $\mathbf{D}) \mathrm{CD}^{+}{ }^{+} \mathrm{T}$ cells were treated as described in Methods to measure anti-CD3-induced $\left[\mathrm{Ca}^{+2}\right]$ flux (C). Cells with [Ca+2] levels above background were considered as responding to the stimulation (D). Difference in peak $\left[\mathrm{Ca}^{+2}\right]$ levels between WT and $\mathrm{Bim}^{-/}$cells is statistically significant $\left({ }^{*} P<0.01\right)$. Difference in the percentage of cells responding is not statistically significant. Experiments were repeated 3 times with similar results.

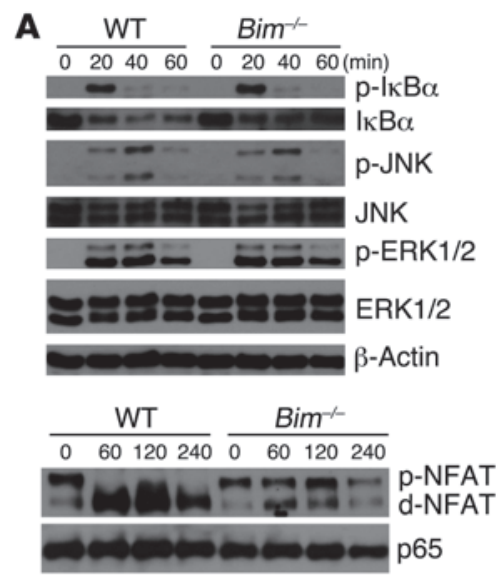

this issue, we first examined the frequencies of myelin- and insulin-reactive $\mathrm{T}$ cells in WT and $\mathrm{Bim}^{-/-}$mice by limiting dilution analysis (LDA) (25-27). Thus, splenic T cells were diluted in 2-fold steps in 96-well plates and mixed with a variable number of feeder cells (irradiated splenic cells). IL-2 and a self antigen (inactivated insulin, myelin basic protein [MBP], or MOG38-50 peptide) were added to each culture to expand the specific $T$ cells. Fourteen days later, cells were restimulated with the same self antigens and their proliferation measured. Fractions of negative and positive cultures were used to calculate the frequencies of antigen-reactive $\mathrm{T}$ cells by $X^{2}$ minimization (25-27). Unexpectedly, we found that the frequency of $\mathrm{T}$ cells responding to each of the self antigens was significantly reduced in $\mathrm{Bim}^{-/}$mice (Table 1). These results indicate that, regardless of the potential roles of Bim in the negative selection of myelin- and insulin-specific $\mathrm{T}$ cells, the "effective frequency" of these cells, i.e., the frequency of cells that can mount a detectable response to their antigens, is reduced in $\mathrm{Bim}^{-1-}$ mice. Because $\mathrm{Bim}^{-1-} \mathrm{T}$ cells have significant defects in their responses to antigen stimulation, which are measured by LDA, the reduced "effective frequency" of self-reactive $\mathrm{T}$ cells in $\mathrm{Bim}^{-/}$mice may sim-

\section{(B)}

\section{Figure 4}

CD4 ${ }^{+}$T cells isolated as in Figure 3 were stimulated with $(A-C) 5 \mu \mathrm{g} / \mathrm{ml}$ plate-bound anti-CD3 and $2 \mu \mathrm{g} / \mathrm{ml}$ soluble anti-CD28 or (D) $50 \mathrm{ng} / \mathrm{ml}$ levels were determined by quantitative real-time PCR. The experimere repeated 3 times with similar results. The differences for all cultures with anti-CD3 and anti-CD28 (A-C) but not for those with PMA and ionomycin (D). Error bars represent SD. 
Table 1

Effective frequencies of autoreactive T cells

\begin{tabular}{lccc} 
Antigens & Genotypes & $\begin{array}{c}\text { Responders } \\
\text { per } \mathbf{1 0}^{7} \text { T cells }\end{array}$ & $\begin{array}{c}\text { Responders } \\
\text { per spleen }\end{array}$ \\
M0G38-50 & WT & 57.5 & 457.7 \\
MOG38-50 & Bim $^{--}$ & 46.2 & 1177.3 \\
Insulin & WT & 52.4 & 208.3 \\
Insulin & Bim- $^{--}$ & 4.6 & 41.8 \\
MBP & WT & 17.8 & 70.9 \\
MBP & Bim $^{--}$ & 6.8 & 60.9 \\
\hline
\end{tabular}

ply be a result of their reduced responsiveness. However, because the total number of splenocytes in $\mathrm{Bim}^{-/}$mice was increased as compared with those in WT mice, $\mathrm{Bim}^{-/}$mice do not have significantly reduced total numbers of self-reactive $\mathrm{T}$ cells, with the exception of insulin-reactive cells (Table 1).

\section{Discussion}

Tissue homeostasis depends on the tight control of the balance between cell proliferation and death. There is a growing list of proteins, such as c-Myc, p53, Ras, and NF- $\kappa$ B, that have dual roles in cell-cycle control and apoptosis. Recently, the Bcl2 family of proteins has also been implicated in controlling cell-cycle progression and proliferation. The first connection between $\mathrm{Bcl} 2$ and cell-cycle control was discovered in murine bone marrow-derived Baf3 cells. Overexpression of $\mathrm{Bcl} 2$ resulted in an arrest at the $\mathrm{G}_{1}$ phase of the cell cycle (28). Further experiments revealed that $\mathrm{T}$ and $\mathrm{B}$ cells from $\mathrm{Bcl} 2$ transgenic mice entered the cell cycle with delayed kinetics and thymocyte turnover was delayed (28). On the other hand, $\mathrm{T}$ cells deficient in $\mathrm{Bcl} 2$ demonstrated increased cell-cycle progression and proliferation, whereas overexpression of Bax blocked the antiproliferative effect of $\mathrm{Bcl} 2$ (29).

In addition to regulating cell cycle and apoptosis, $\mathrm{Bcl} 2$ family members have also been implicated in controlling cell activation. Both $\mathrm{Bcl} 2$ and $\mathrm{Bcl}-\mathrm{xL}$ can form a protein complex with $\mathrm{IP}_{3} \mathrm{R}$ on the ER and modulate ER $\mathrm{Ca}^{+2}$ release $(23,24)$. It is believed that phosphorylation of $\mathrm{Bcl} 2$ by JNK at the ER membrane may regulate the antiapoptotic activity of $\mathrm{Bcl} 2$ negatively, causing decreased binding to BH3-only proteins and increasing $\mathrm{ER} \mathrm{Ca}^{+2}$ content (30). Bax and $\mathrm{Bak}$ are also implicated in controlling $\mathrm{ER} \mathrm{Ca}^{+2}$ homeostasis and the regulation of $\mathrm{T}$ cell proliferation (31). Bax and Bak double-knockout cells are defective in $\mathrm{ER} \mathrm{Ca}^{+2}$ flux upon stimulation, which appears to be dependent on $\mathrm{Bcl} 2$ and $\mathrm{IP}_{3} \mathrm{R}(23)$. The balance between antiapoptotic and proapoptotic proteins at the ER may determine the steady state of $\mathrm{ER} \mathrm{Ca}^{+2}$ content and have a direct impact on the amount of $\mathrm{Ca}^{+2}$ released after stimulation. This may in turn affect many cellular processes, including cell activation and proliferation.

Our data indicate that the balance between antiapoptotic and proapoptotic $\mathrm{Bcl} 2$ family members extends beyond the control of apoptosis and proliferation. Bim and $\mathrm{Bcl} 2$ may act in opposition to alter $T$ cell activation through modulation of ER calcium flux. In order for Bcl 2 members to adequately control apoptosis, they must sequester proapoptotic proteins to prevent cell death. The amount of free $\mathrm{Bcl} 2$ available to bind $\mathrm{IP}_{3} \mathrm{R}$ is likely dependent on the levels of proapoptotic proteins, such as Bim. Under normal conditions in $\mathrm{T}$ cells, a fraction of $\mathrm{Bcl} 2$ protein is available to bind to $\mathrm{IP}_{3} \mathrm{R}$ on the ER. By interacting with $\mathrm{Bcl} 2$, Bim can affect not only cell death but also the amount of free $\mathrm{Bcl} 2$ available to bind $\mathrm{IP}_{3} \mathrm{R}$. This in turn controls other cellular responses such as $\mathrm{T}$ cell activation, as we demonstrated here. Because Bim has been found to be associated with ER membranes, it is also possible that it may modulate ER calcium release directly (32).

Thus, Bim may regulate the fates of autoreactive $\mathrm{T}$ cells through 2 different pathways: (a) the mitochondria apoptosis pathway, through which it mediates negative selection of autoreactive immature T cells (11); and (b) the calcium/NFAT pathway, through which it controls the activation of mature T cells. However, many $\mathrm{T}$ cells recognizing self antigens, e.g., MOG, may not undergo thymic negative selection. Indeed, MOG peptide-specific $\mathrm{T}$ cells are not deleted or tolerized in transgenic mice expressing the MOG-specific TCR (33). Therefore, Bim-mediated thymic selection may not operate in the MOG-induced EAE model studied here. Although Bim may be involved in the thymic deletion of $T$ cells recognizing MBP and insulin, our demonstration that the "effective frequency" of these cells was decreased in $\mathrm{Bim}^{-/-}$mice indicates that Bim's effect on T cell activation may prevail in vivo. This may explain why $\mathrm{Bim}^{-/-}$mice, despite their defect in negative selection, do not reject their own organs. Similar results have been reported for $\mathrm{Bax}^{-/-}$mice following immunization with a MOG peptide (34). Neither young nor old Bax $x^{-/-}$mice develop lymphadenopathy or spontaneous autoimmune diseases (35). But both clinical manifestations of EAE and oligodendrocyte death were reduced in $\mathrm{Bax}^{-/-}$mice (34). Thus, deficiency in either Bim or Bax is sufficient to prevent EAE.

In summary, our unexpected observation that $\mathrm{Bim}^{-1-}$ mice are resistant to EAE and T1D led to the discovery of what we believe is a previously unrecognized function of Bim in T cell activation. This finding will have significant ramifications for our understanding of the mechanisms of immune homeostasis and autoimmune diseases.

\section{Methods}

Mice and cell transfer. Bim ${ }^{-1}$ 129/SvJ mice were generated by replacing the BH3-encoding exon of the Bim gene with a neo cassette flanked by LoxP sites as described (17). The neo cassette was later removed from $\mathrm{Bim}^{-/}$mice by crossing them with the Cre-expressing deleter mice (17). To generate $\mathrm{Bim}^{-/-}$ C57BL/ 6 mice, $\mathrm{Bim}^{-/+} 129 / \mathrm{SvJ} \times \mathrm{C} 57 \mathrm{BL} / 6 \mathrm{~F} 2$ mice were backcrossed to $\mathrm{C} 57 \mathrm{BL} / 6$ background for 10 generations. To generate $\mathrm{Bim}^{-/+} \mathrm{NOD}$.C57BL/6 congenic mice, $\mathrm{Bim}^{-/+}$mice were backcrossed to NOD background for 8 generations. $\mathrm{Bim}^{-/-}$congenic mice were then generated by crossing $\mathrm{Bim}^{-/+}$ mice. The Bim gene mutation was tracked by genomic PCR as described (17). To generate bone marrow chimeric mice, recipient $\mathrm{CD} 45.1^{+}$or $\mathrm{CD} 45.2^{+}$ C57BL/ 6 mice were irradiated with 2 doses of 5 Gy each. They were then i.v. injected with $10^{7}$ bone marrow cells collected from CD $45.1^{+}$or CD $45.2^{+}$ donor mice. Eight weeks following bone marrow reconstitution, mice were used for experiments described in this study. For T cell transfer, $10^{7} \mathrm{CD}^{+}$ $\mathrm{T}$ cells isolated from spleens were injected into $\mathrm{Rag} 1^{-/-} \mathrm{C} 57 \mathrm{BL} / 6$ mice through the tail vein. Twenty-four hours after the transfer, mice were used for the disease studies. All procedures were preapproved by the University of Pennsylvania Institutional Animal Care and Use Committee. Bim ${ }^{-1-}$ mice were a gift from Andreas Strasser and Bouillet Philippe (The Walter and Eliza Hall Institute of Medical Research, Melbourne, Australia).

Cell culture and reagents. Splenocytes or $\mathrm{CD}^{+} \mathrm{T}$ cells isolated by magnetic sorting were cultured in complete DMEM containing 10\% FBS, $100 \mathrm{U} / \mathrm{ml}$ penicillin, $100 \mu \mathrm{g} / \mathrm{ml}$ streptomycin, $30 \mu \mathrm{M} \beta$-mercaptoethanol, $1 \mathrm{mM}$ sodium pyruvate, $10 \mathrm{mM}$ HEPES, and $1 \times$ nonessential amino acids (36). 
Anti-CD3 and anti-CD28 were purchased from eBioscience. MOG38-50 peptide was synthesized by Invitrogen. Pertussis toxin was purchased from List Biological Laboratories Inc. CFA was purchased from DIFCO Laboratories. Anti-NFATc2 (4G6-C5) antibody was from Santa Cruz Biotechnology

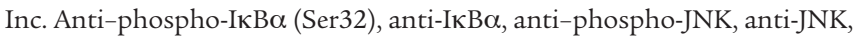
anti-phospho-p44/42 MAPK, and anti-p44/42 MAPK antibodies were from Cell Signaling Technology. Anti-p65 antibody was from eBioscience.

Induction and evaluation of EAE. EAE was induced as described (37). In brief, mice first received a s.c. immunization with $300 \mu \mathrm{g}$ MOG38-50 peptide emulsified in CFA and an i.v. injection of $200 \mathrm{ng}$ pertussis toxin. A second injection of $200 \mathrm{ng}$ pertussis toxin was given 48 hours later. Mice were examined daily for clinical signs of EAE and scored as follows: 0 , no disease; 1 , tail paralysis; 2 , hind limb weakness; 3 , hind limb paralysis; 4, hind limb plus forelimb paralysis; and 5, moribund or dead. For pathological analysis, spinal cord and brain were sectioned and stained with $\mathrm{H} \& \mathrm{E}$ or luxol fast blue and cresyl violet. The degree of inflammation was scored by a blinded observer as follows: 0 , no white matter infiltration or demyelination; 1 , mild infiltration; 2 , moderate infiltration; and 3 , extensive infiltration with demyelination throughout the white matter.

Induction and evaluation of T1D. To induce diabetes with STZ, C57BL/6 mice were injected i.p. for 5 consecutive days with $40 \mathrm{mg} / \mathrm{kg} \mathrm{STZ}$. To induce diabetes with CY, NOD mice, 6 to 7 weeks old, were injected with $200 \mathrm{mg} / \mathrm{kg}$ of $\mathrm{CY}$ on days 0 and 7. Tail-vein blood glucose levels were measured twice a week with a FreeStyle blood glucose meter (Abbott). Mice were considered diabetic when glucose levels were greater than or equal to $250 \mathrm{mg} / \mathrm{dl}$ on 2 consecutive tests. For pathological analysis, pancreata were sectioned and stained with H\&E. The degree of islet inflammation was graded as follows: 0 , no inflammation; 1 , peri-insulitis with mononuclear cell infiltration affecting $25 \%$ or less of the circumference; 2 , peri-insulitis with mononuclear cell infiltration affecting more than $25 \%$ of the circumference; 3 , moderate insulitis with intraislet mononuclear cell infiltration but good preservation of islet architecture; and 4, severe insulitis with numerous intraislet inflammatory cells and loss of normal islet architecture.

LDA. Splenocytes were isolated from 8 WT and 4 Bim-knockout C57BL/6 mice at 6 weeks of age. Cells were diluted in 2-fold steps and mixed with variable numbers of feeder cells (irradiated splenocytes from C57BL/6 mice) so that the final concentration of cells was $5 \times 10^{6}$ cells/well. Cells were cultured in 96-well plates in complete medium for 14 days with 50 units $/ \mathrm{ml}$ of recombinant IL-2 and $50 \mu \mathrm{g} / \mathrm{ml}$ of insulin (heat inactivated), MBP, or MOG peptide. A total of 24 wells were used for each dilution, with an equal number of wells cultured without antigen. After incubation, cells were washed and split into 2 separate cultures mixed with $5 \times 10^{5}$ feeder cells/well. Cells were cultured for another 3 days with or without the respective antigens. During the last 16 hours of the culture, $\left[{ }^{3} \mathrm{H}\right]$-thymidine was added. Radioactivity was measured using a beta counter. Cultures were considered positive when the cpm were 3 SDs above the means of cultures without antigen. The frequency of responders was calculated by plotting the log of the fraction of negative cultures versus the cell dose. A line was fitted to the plotted points. The frequency of precursors was extrapolated directly by drawing a line from 0.37 to the point where that line intersected with the fitted line.

Real-time PCR. Total RNA was extracted using TRIzol reagent (Invitrogen). cDNA was synthesized using reverse transcriptase II (Invitrogen). Realtime quantitative PCR was performed using the SYBR Green Master Mix (Applied Biosystems). Data were normalized to $\beta$-actin mRNA.

Enzyme-linked immunosorbent assay. Antibodies used in ELISA were purchased from BD Pharmingen, including purified and biotinylated rat antimouse IL-2, IL-4, IL-6, IFN- $\gamma$, and IL-17A. Quantitative ELISA was performed using paired $\mathrm{mAbs}$ specific for corresponding cytokines according to the manufacturer's recommendations.

Western blot. Total cell lysate was prepared by suspending cells in RIPA buffer containing $150 \mathrm{mM} \mathrm{NaCl}, 10 \mathrm{mM}$ Tris (pH 7.4), 0.1\% SDS, $1 \%$ Triton $\mathrm{X}-100,1 \%$ sodium deoxycholate, $100 \mu \mathrm{M} \mathrm{Na}_{3} \mathrm{VO}_{4}, 5 \mathrm{mM}$ EDTA, $1 \mathrm{mM}$ PMSF, and protease inhibitor cocktail. Proteins ( $20 \mu \mathrm{g} / \mathrm{lane})$ were resolved by SDS-PAGE, transferred to a nitrocellulose membrane, and blotted with specific antibodies (36).

Calcium measurement. Single-cell suspensions of mesenteric lymph nodes, $10^{7}$ cells per group, were washed twice in RPMI containing $2 \%$ FBS and resuspended in the staining buffer, which contained $1 \mathrm{ml}$ RPMI, $10 \mu \mathrm{l} \mathrm{FBS}$, $20 \mu \mathrm{l}$ probenecid, $1.5 \mu \mathrm{l}$ indo- 1 in DMSO, $4 \mu \mathrm{l}$ anti-CD4-APC, $4 \mu \mathrm{l}$ biotin anti-CD3, and $4 \mu \mathrm{l}$ biotin anti-CD4. Cells were incubated in the dark at $30^{\circ} \mathrm{C}$ for 30 minutes. After incubation, cells were washed and resuspended in cold serum-free RPMI. Analysis was performed on an LSR II Flow Cytometer (BD). Samples were first run for 90 seconds and then treated with a warm mix of RPMI and streptavidin (1:50 dilution) to enable antibody cross-linking. Samples were run for an additional 3.5 minutes. Analysis was performed using FlowJo software, version 7 (Tree Star).

Statistics. Disease severity, day of onset, calcium flux, and cytokine concentrations were analyzed by 2 -tailed Student's $t$ test. Disease scores were analyzed by Mann-Whitney $U$ test. $P<0.05$ was considered significant.

\section{Acknowledgments}

The authors thank Andreas Strasser and Bouillet Philippe (The Walter and Eliza Hall Institute of Medical Research, Melbourne, Australia) for kindly providing the $\mathrm{Bim}^{-/-}$mice; Andreas Strasser, Shijun Zheng, Li Li, Qingguo Ruan, and Xiaochun Wan for valuable discussions; and the Penn Center for Musculoskeletal Disorders for technical support. This work was supported by grants from the NIH (AI50059, DK070691, and AI069289).

Received for publication October 1, 2008, and accepted in revised form March 3, 2009.

Address correspondence to: Youhai H. Chen, 713 Stellar-Chance Laboratories, Department of Pathology and Laboratory Medicine, University of Pennsylvania School of Medicine, 422 Curie Blvd., Philadelphia, Pennsylvania 19104, USA. Phone: (215) 898-4671; Fax: (215) 573-3434; E-mail: yhc@mail.med.upenn.edu.
1. Puthalakath, H., and Strasser, A. 2002. Keeping killers on a tight leash: transcriptional and posttranslational control of the pro-apoptotic activity of BH3-only proteins. Cell Death Differ. 9:505-512.

2. Strasser, A., et al. 2000. The role of bim, a proapoptotic BH3-only member of the Bcl-2 family in celldeath control. Ann. N. Y. Acad. Sci. 917:541-548.

3. Putcha, G.V., et al. 2003. JNK-mediated BIM phosphorylation potentiates BAX-dependent apoptosis. Neuron. 38:899-914.

4. Budihardjo, I., Oliver, H., Lutter, M., Luo, X., and Wang, X. 1999. Biochemical pathways of caspase activation during apoptosis. Annu. Rev. Cell Dev.
Biol. 15:269-290.

5. Coultas, L., and Strasser, A. 2003. The role of the $\mathrm{Bcl}-2$ protein family in cancer. Semin. Cancer Biol. 13:115-123.

6. Marsden, V.S., and Strasser, A. 2003. Control of apoptosis in the immune system: Bcl-2, BH3-only proteins and more. Annu. Rev. Immunol. 21:71-105.

7. Michaelidis, T.M., et al. 1996. Inactivation of bcl-2 results in progressive degeneration of motoneurons, sympathetic and sensory neurons during early postnatal development. Neuron. 17:75-89.

8. O'Connor, L., et al. 1998. Bim: a novel member of the Bcl-2 family that promotes apoptosis. EMBO J.
17:384-395.

9. Marani, M., Tenev, T., Hancock, D., Downward, J., and Lemoine, N.R. 2002. Identification of novel isoforms of the $\mathrm{BH} 3$ domain protein Bim which directly activate Bax to trigger apoptosis. Mol. Cell. Biol. 22:3577-3589.

10. Puthalakath, H., Huang, D.C., O’Reilly, L.A., King, S.M., and Strasser, A. 1999. The proapoptotic activity of the Bcl-2 family member Bim is regulated by interaction with the dynein motor complex. Mol. Cell. 3:287-296.

11. Bouillet, P., et al. 2002. BH3-only Bcl-2 family member Bim is required for apoptosis of autoreac- 
tive thymocytes. Nature. 415:922-926.

12. Harris, C.A., and Johnson, E.M., Jr. 2001. BH3-only $\mathrm{Bcl}-2$ family members are coordinately regulated by the JNK pathway and require Bax to induce apoptosis in neurons. J. Biol. Chem. 276:37754-37760.

13. Putcha, G., et al. 2001. Induction of BIM, a proapoptotic BH3-only BCL-2 family member, is critical for neuronal apoptosis. Neuron. 29:615-628.

14. Whitfield, J., Neame, S.J., Paquet, L., Bernard, O., and Ham, J. 2001. Dominant-negative c-Jun promotes neuronal survival by reducing BIM expression and inhibiting mitochondrial cytochrome $\mathrm{c}$ release. Neuron. 29:629-643.

15. Harada, H., Quearry, B., Ruiz-Vela, A., and Korsmeyer, S.J. 2004. Survival factor-induced extracellular signal-regulated kinase phosphorylates BIM, inhibiting its association with BAX and proapoptotic activity. Proc. Natl. Acad. Sci. U. S. A. 101:15313-15317.

16. Lei, K., and Davis, R.J. 2003. JNK phosphorylation of Bim-related members of the Bcl2 family induces Bax-dependent apoptosis. Proc. Natl. Acad. Sci.U.S. A. 100:2432-2437.

17. Bouillet, P., et al. 1999. Proapoptotic $\mathrm{Bcl}-2$ relative Bim required for certain apoptotic responses, leukocyte homeostasis, and to preclude autoimmunity. Science. 286:1735-1738.

18. Hildeman, D.A., et al. 2002. Activated T cell death in vivo mediated by proapoptotic bcl-2 family member bim. Immunity. 16:759-767.

19. Hilliard, B., et al. 2001. Roles of TNF-related apoptosis-inducing ligand in experimental autoimmune encephalomyelitis. J. Immunol. 166:1314-1319.

20. Lukic, M.L., Stosic-Grujicic, S., and Shahin, A. 1998.
Effector mechanisms in low-dose streptozotocininduced diabetes. Dev. Immunol. 6:119-128.

21. Lamhamedi-Cherradi, S.-E., Zheng, S., Tisch, R., and Chen, Y.H. 2003. Critical roles of tumor necrosis factor-related apoptosis-inducing ligand in type I diabetes. Diabetes. 52:2274-2278.

22. Lutsiak, M.E., et al. 2005. Inhibition of CD4(+)25+ $T$ regulatory cell function implicated in enhanced immune response by low-dose cyclophosphamide. Blood. 105:2862-2868.

23. Oakes, S.A., et al. 2005. Proapoptotic BAX and BAK regulate the type 1 inositol trisphosphate receptor and calcium leak from the endoplasmic reticulum. Proc. Natl. Acad. Sci. U. S. A. 102:105-110.

24. Chen, R., et al. 2004. Bcl-2 functionally interacts with inositol 1,4,5-trisphosphate receptors to regulate calcium release from the ER in response to inositol 1,4,5-trisphosphate. J. Cell Biol. 166:193-203.

25. Chen, Y., Inobe, J., and Weiner, H.L. 1995. Induction of oral tolerance to MBP in CD8-depleted mice. J. Immunol. 155:910-916.

26. Petrow, P.K., Thoss, K., Henzgen, S., Katenkamp, D., and Bräuer, R. 1996. Limiting dilution analysis of the frequency of autoreactive lymph node cells isolated from mice with antigen-induced arthritis. J. Autoimmun. 9:629-635.

27. Taswell, C. 1981. Limiting dilution assays for the determination of immunocompetent cell frequencies. I. Data analysis. J. Immunol. 126:1614.

28. Mazel, S., Burtrum, D., and Petrie, H.T. 1996. Regulation of cell division cycle progression by bcl-2 expression: a potential mechanism for inhibition of programmed cell death. J. Exp. Med. 183:2219-2226.

29. O’Reilly, L.A., Huang, D.C., and Strasser, A. 1996.
The cell death inhibitor Bcl-2 and its homologues influence control of cell cycle entry. EMBO J. 15:6979-6990.

30. Bassik, M.C., Scorrano, L., Oakes, S.A., Pozzan, T., and Korsmeyer, S.J. 2004. Phosphorylation of BCL-2 regulates ER Ca2+ homeostasis and apoptosis. EMBO J. 23:1207-1216.

31. Jones, R.G., et al. 2007. The proapoptotic factors Bax and Bak regulate $\mathrm{T}$ Cell proliferation through control of endoplasmic reticulum $\mathrm{Ca}(2+)$ homeostasis. Immunity. 27:268-280.

32. Morishima, N., Nakanishi, K., Tsuchiya, K., Shibata, T., and Seiwa, E. 2004. Translocation of Bim to the endoplasmic reticulum (ER) mediates ER stress signaling for activation of caspase-12 during ER stressinduced apoptosis. J. Biol. Chem. 279:50375-50381.

33. Bettelli, E., et al. 2003. Myelin oligodendrocyte glycoprotein-specific $\mathrm{T}$ cell receptor transgenic mice develop spontaneous autoimmune optic neuritis. J. Exp. Med. 197:1073-1081.

34. Lev, N., Barhum, Y., Melamed, E., and Offen, D. 2004. Bax-ablation attenuates experimental autoimmune encephalomyelitis in mice. Neurosci. Lett. 359:139-142.

35. Knudson, C., Tung, K.S., Tourtellotte, W.G., Brown, G.A., and Korsmeyer, S.J. 1995. Bax-deficient mice with lymphoid hyperplasia and male germ cell deat. Science. 270:96-99.

36. Sun, H., et al. 2008. TIPE2, a negative regulator of innate and adaptive immunity that maintains immune homeostasis. Cell. 133:415-426.

37. Hilliard, B., et al. 2002. Critical roles of c-Rel in autoimmune inflammation and helper $\mathrm{T}$ cell differentiation. J. Clin. Invest. 110:843-850. 